\title{
PENGARUH FAKTOR-FAKTOR AUDIT INTERNAL TERHADAP KINERJA STAF QUALITY CONTROL (Studi Kasus PT. Pabrik Kertas Tjiwi Kimia Tbk. di Sidoarjo)
}

*Aga Rifki Anggoman, Masyhad, Tri Lestari

Program Studi Akuntansi Fakultas Ekonomi dan Bisnis

Universitas Bhayangkara Surabaya, Indonesia

DOI: 10.46821 /equity.v1i1.5

\begin{abstract}
ABSTRAK
Penelitian ini bertujuan untuk mengetahui Pengaruh Faktor-Faktor Audit Internal secara parsial dan simultan Terhadap Kinerja Staf Quality Control pada PT. Pabrik Kertas Tjiwi Kimia Sidoarjo. Variabel independen penelitian ini adalah profesionalisme, ruang lingkup dan independensi. Sedangkan untuk variabel dependen penelitian ini adalah kinerja staf quality control. Teknik pengumpulan data dilakukan menggunakan metode kuesioner. Data dianalisis menggunakan software SPSS 18.0. Persamaan regresi penelitian ini adalah regresi linier berganda dan teknik pengujian data meliputi uji validitas, uji reliabelitas dan uji asumsi klasik. Hasil penelitian ini menunjukan bahwa profesionalisme, ruang lingkup dan independensi audit internal berpengaruh positif signifikan terhadap kinerja staf quality control.
\end{abstract}

Kata kunci: Kinerja staf quality control, Profesionalisme, Ruang lingkup dan Independensi audit internal

\begin{abstract}
This study aims to determine the effect of partial and simultaneous Internal Audit Factors on Quality Control Staff Performance at PT. Tjiwi Kimia Paper Factory Sidoarjo. The independent variable of this study is professionalism, scope and independence. While for the dependent variable of this study is the performance of quality control staff. Data collection techniques were carried out using the questionnaire method. Data were analyzed using SPSS 18.0 software. The regression equation of this study is multiple linear regression and data testing techniques include validity test, reliability test and classic assumption test. The results of this study indicate that professionalism, scope and independence of internal audit have a significant positive effect on the performance of quality control staff.
\end{abstract}

Keywords: Quality control staff performance, Professionalism, Scope and Independence of internal audit

*Corresponding Author:

Email: agarifki14@gmail.com 


\section{PENDAHULUAN}

Audit internal mempunyai peran yang sangat vital, karena posisinya sebagai pihak penjamin yang menjamin bahwa laporan yang telah dievaluasi. Audit internal juga mempunyai peran sebagai konsultasi yang dimana dapat memberikan saran kepada pihak manajemen risiko dan komisaris dalam hal pembuatan kebijakan yang berhubungan dengan kegiatan strategis perusahaan. Apabila peran audit internal ini dapat dijalankan, maka tata kelola perusahaan telah dilakukan dengan benar dan sesuai. Manajemen dan Dewan Komisaris pun dapat menilai tingkat kinerja dari audit intenal perusahaan apakah sesuai dengan ekspektasi dan keinginan dari Manajemen dan Dewan Komisaris. Pengertian audit internal menurut Hery (2017:238) adalah: "Audit internal adalah suatu fungsi penelian yang dikembangkan secara bebas dalam organisasi untuk menguji dan mengevaluasi kegiatan-kegiatan sebagai wujud pelayanan terhadap organisasi perusahaan. Pemeriksaan intern melaksanakan aktivitas penelian yang bebas dalam suatu organisasi untuk menelaah kembali kegiatan-kegiatan dalam bidang akuntansi, keuangan dan bidang-bidang operasi laiinya sebagai dasar pemberian pelayanannya pada manajemen."

Berikut ini merupakan penjelasan dari beberapa faktor dalam audit internal yang antara lain: Menurut Rahma (2012) dalam Kompiang (2013), profesionalisme auditor internal adalah: "Profesionalisme adalah sikap tanggungjawab dari seorang auditor dalam menyelesaikan pekerjaan auditnya dengan keikhlasan hatinya sebagai seorang auditor."

Menurut Standar Praktik IIA seksi 300 tentang Ruang Lingkup Pekerjaan dalam Amin (2015:18) adalah sebagai berikut: "Ruang lingkup pekerjaan audit internal harus mencakup pemeriksaan dan evaluasi atas kecukupan serta efektivitas sistem pengendalian internal organisasi dan kualitas kinerja dalam melaksanakan tanggung jawab yang diberikan".

Sebagaimana diatur dalam Standar Audit 1100 (IIA, 2012) dalam Elvira Zeyn (2013 : 20), aktifitas audit internal harus independen, dan auditor internal harus bersikap objektif dalam melaksanakan pekerjaan pemeriksaan.

Kinerja adalah hasil atau tingkat keberhasilan seseorang secara keseluruhan selama periode tertentu dalam melaksanakan tugas yang diberikan kepada seseorang yang dibandingkan dengan berbagai kemungkinan, seperti standar hasil kerja, target atau sasaran atau kriteria yang telah ditentukan terlebih dahulu telah disepakati bersama (Romahtun 2016).

Dalam penelitian ini peneliti menggunakan serangkaian uji antara lain Uji Validitas dan Uji Reliabilitas, Uji t dan Uji F. Tujuan dalam penelitian ini untuk mengetahui apakah ada pengaruh secara simultan dan parsial faktor-faktor audit internal terhadap kinerja staf quality control PT. Pabrik Kertas Tjiwi Tbk Sidoarjo. 
METODE PENELITIAN

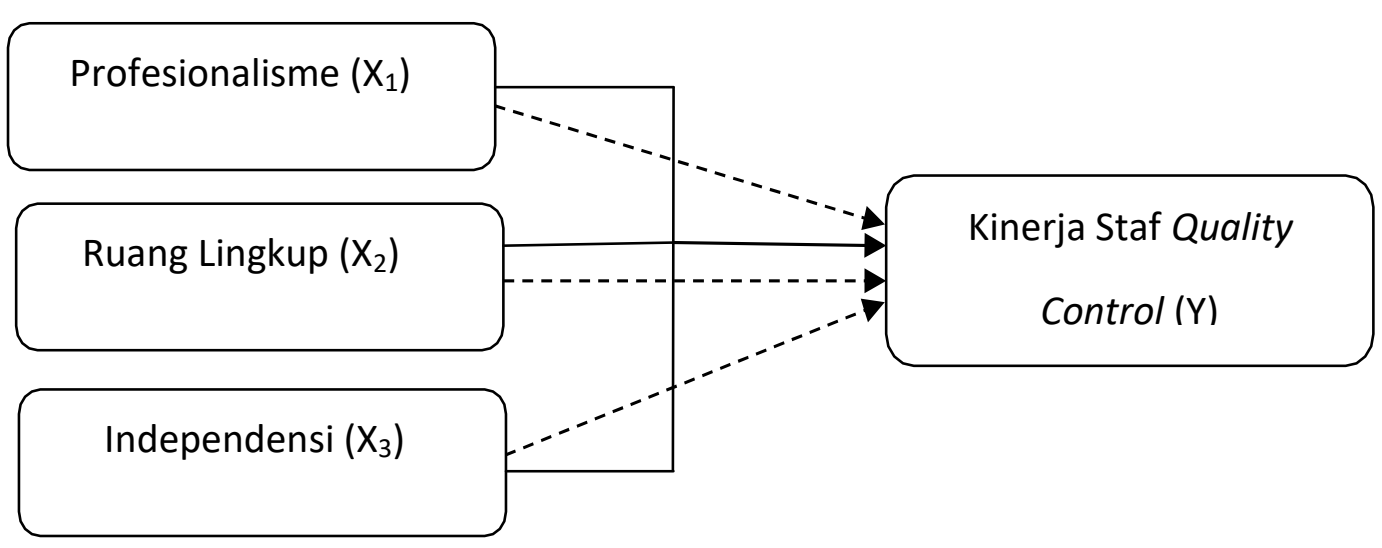

Sumber : Data diolah peneliti (2019)

\section{Gambar 1 Kerangka Konseptual}

Keterangan :

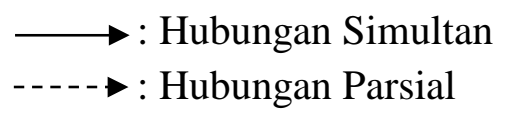

Berdasarkan rumusan masalah, tujuan, tinjauan teoritis dan kerangka pemikiran di atas, maka dapat diajukan hipotesis sebagai berikut:

H1: Profesionalisme, ruang lingkup dan independensi audit internal berpengaruh secara simultan terhadap kinerja staf Quality Control di PT Pabrik Kertas Tjiwi Kimia Tbk Sidoarjo.

$\mathrm{H} 2$ : Profesionalisme, ruang lingkup dan independensi audit internal berpengaruh secara parsial terhadap kinerja staf Quality Control di PT Pabrik Kertas Tjiwi Kimia Tbk Sidoarjo.

Populasi dalam penelitian ini adalah Staf Quality Control di PT Pabrik Kertas Tjiwi Kimia Tbk di Sidoarjo. Pengambilan sampel dalam penelitian ini menggunakan rumus slovin sehingga jumlah sampel penelitian ini adalah sebesar 29 responden.

Teknik pengumpulan data yang dipergunakan dalam penelitian ini diantaranya :

1. Data primer

Adapun data yang diperoleh dengan cara penelitian yaitu : Kuesioner atau daftar pertanyaan yaitu dengan cara membuat daftar pertanyaan yang kemudian disebarkan pada para responden secara langsung sehingga hasil pengisiannnya akan lebih jelas dan akurat. Daftar pertanyaan mengenai gambaran umum, perhatian dan pendapat responden mengenai seberapa besar pengaruh faktorfaktor audit internal terhadap kinerja staf Quality Control di PT Pabrik Kertas Tjiwi Kimia Tbk. 
2. Data sekunder

Data ini merupakan pendukung yang berhubungan dengan penelitian yang diperoleh dari:

a. Sejarah, dan profil PT Pabrik Kertas Tjiwi Kimia Tbk

b. Jurnal dan hasil penelitian yang terdahulu yang berhubungan dengan topik permasalahan yang diteliti.

Dalam penelitian ini analisis yang digunakan antara lain : Analisis Regresi Linier Berganda dan Analisis Korelasi Parsial (Person Product Moment)

\section{HASIL DAN PEMBAHASAN}

\section{Analisis Data}

\section{Analisis Regresi Linier Berganda}

Berikut persamaan Regresi Linear Berganda:

$\mathrm{Y}=-2.942+0,276 \mathrm{X} 1+0,861 \mathrm{X} 2+0,902 \mathrm{X} 3$

Keterangan :

$\mathrm{Y}=$ Kinerja Staf Quality Control

$\mathrm{X} 1$ = Profesionalisme X2 = Ruang Lingkup X3 = Independensi

Nilai constant (Y) sebesar -2.942 artinya jika variabel profesionalisme, ruang lingkup dan independensi bernilai 0 (nol), maka nilai variabel kinerja staf quality control (Y) akan berada pada angka -2.942. Atau jika tidak ada pengaruh dari variabel - variabel bebas profesionalisme, ruang lingkup dan independensi dan maka kinerja staf quality control mengalami perubahan (Tabel 1).

\section{Analisis Korelasi Parsial (Person Product Moment)}

Pada tabel diperoleh nilai Adjusted $\mathrm{R}$ Square $=0,912=91,2 \%$. Ini berarti variabel bebas Profesionalisme, Ruang Lingkup dan Independensi secara bersama-sama mempengaruhi variabel bebas Kinerja Karyawan sebesar 91,2\% dan sisanya $8,8 \%$ dipengaruhi oleh variabel lain yang tidak masuk dalam penelitian ini (Tabel 2).

Tabel 1. Analisis Regresi Linear Berganda Coefficients $a$

\begin{tabular}{|c|c|c|c|c|c|c|}
\hline & \multirow[b]{2}{*}{ Model } & \multicolumn{2}{|c|}{$\begin{array}{c}\text { Unstandardized } \\
\text { Coefficients }\end{array}$} & \multirow{2}{*}{$\begin{array}{c}\text { Standardized } \\
\text { Coefficients } \\
\text { Beta }\end{array}$} & \multirow[b]{2}{*}{$T$} & \multirow[b]{2}{*}{ Sig. } \\
\hline & & $B$ & Std. Error & & & \\
\hline \multirow[t]{4}{*}{$\overline{1}$} & (Constant) & -2.942 & 1.385 & & -2.124 & .047 \\
\hline & Profesionalisme & .276 & .087 & .235 & 3.176 & .004 \\
\hline & Ruang Lingkup & .861 & .107 & .490 & 8.073 & .000 \\
\hline & Independensi & .902 & .143 & .485 & 6.302 & .000 \\
\hline
\end{tabular}

a. $\quad$ Dependent Variable: Kinerja Staf Quality Control

Sumber : Data Primer (2019) 
Aga Rifki Anggoman dkk., Pengaruh Faktor Audit Internal

Tabel 2. Analisis Korelasi Parsial Model Summary

Vol. 1 No. 12020

\begin{tabular}{ccccc} 
Model & $R$ & $R$ Square & Adjusted $R$ Square & Std. Error of the Estimate \\
\hline 1 & $.960^{\mathrm{a}}$ & .921 & .912 & .755
\end{tabular}

a. Predictors: (Constant), Independensi, Ruang Lingkup, Profesionalisme

Sumber : Data Primer (2019)

Tabel 3. Uji F ANOVA

\begin{tabular}{llrrrrr}
\multicolumn{1}{c}{ Model } & Sum of Squares & Df & Mean Square & $F$ & Sig. \\
\hline Regression & 146.101 & 3 & 48.700 & 97.7 & .000 a \\
Residual & 12.451 & 25 & .498 & 85 & \\
& & 158.552 & 28 & & & \\
& Total & & & & \\
\hline
\end{tabular}

a. Predictors: (Constant), Independensi, Ruang Lingkup, Profesionalisme

b. Dependent Variable: Kinerja Staf Quality Control

Sumber : Data Primer (2019)

\section{Pengujian Hipotesis}

\section{Uji Simultan (Uji F)}

Dengan menggunakan rumus hitung $\mathrm{F}$ tabel $(\mathrm{k} ; \mathrm{n}-\mathrm{k})$ yaitu $(3 ; 26)$ dengan probabilitas 0,10 diperoleh $\mathrm{F}$ tabel sebesar 2,31, maka nilai $\mathrm{F}$ hitung (97.785) > F table (2,31). Untuk uji simultan menggunakan nilai Signifikansi (Sig.) dari output Anova diperoleh nilai Sig. sebesar 0,000, yang berarti 0,000<0,05 (alpha 5\%). Hal ini berarti variabel independen antara variabel profesionalisme, ruang lingkup dan independensi secara bersama-sama berpengaruh terhadap kinerja staf quality control (Tabel 3).

\section{Uji Parsial (Uji t)}

Dengan rumus $t$ tabel $(\alpha / 2 ; \mathrm{n}-\mathrm{k}-1)$ yaitu $(0,05 ; 25)$ diperoleh $\mathrm{t}$ tabel sebesar 1,70814 (Tabel 4).

A. Variabel X1 (Profesionalisme) dapat disimpulkan mengenai uji t (parsial) ditunjukkan dengan hasil perhitungan t hitung yang menunjukkan nilai 3,176. Yang berarti $\mathrm{t}$ hitung $(3,176)>\mathrm{t}$ tabel $(1,70814)$. Untuk uji parsial menggunakan nilai Signifikansi (Sig.) diperoleh nilai Sig. sebesar 0,004, yang berarti $0,004<0,05$ (alpha 5\%). Hal ini berarti variabel profesionalisme secara parsial berpengaruh positif terhadap kinerja staf quality control.

B. Variabel X2 (Ruang Lingkup) dapat disimpulkan mengenai uji t (parsial) ditunjukkan dengan hasil perhitungan t hitung yang menunjukkan nilai 8,073. Yang berarti $\mathrm{t}$ hitung $(8,073)>\mathrm{t}$ tabel $(1,70814)$. Untuk uji parsial menggunakan nilai Signifikansi (Sig.) diperoleh nilai Sig. sebesar 0,000, yang berarti $0,000<0,05$ (alpha 5\%). Hal ini berarti variabel ruang lingkup secara parsial berpengaruh positif terhadap kinerja staf quality control.

C. Variabel X3 (Independensi) dapat disimpulkan mengenai uji $\mathrm{t}$ (parsial) ditunjukkan dengan hasil perhitungan t hitung yang menunjukkan nilai 6,302. 
Yang berarti $\mathrm{t}$ hitung $(6,302)>\mathrm{t}$ tabel $(1,70814)$. Untuk uji parsial menggunakan nilai Signifikansi (Sig.) diperoleh nilai Sig. sebesar 0,000, yang berarti $0,000<0,05$ (alpha 5\%). Hal ini berarti variabel independensi secara parsial berpengaruh positif terhadap kinerja staf quality control.

\section{PEMBAHASAN}

Hasil analisis menunjukan variable bebas yang meliputi Profesionalisme (X1), Ruang Lingkup (X2), dan Independensi (X3) Audit Internal secara bersama-sama (secara simultan) berpengaruh secara signifikan terhadap Kinerja Staf Quality Control (Y) pada PT Pabrik Kertas Tjiwi Kimia Tbk Sidoarjo, karena mempunyai nilai probabilitas $0,000<0,05$.

\section{Pengaruh Profesionalisme Audit Internal Terhadap Kinerja Staf Quality Control}

Bahwa variabel Profesionalisme mempengaruhi variabel Kinerja Staf Quality Control dengan nilai $\mathrm{t}$ hitung positif untuk variabel Profesionalisme 3,176>t tabel sebesar 1,70814 dengan tingkat signifikansi $0,004<0,05$. Berarti variabel Profesionalisme berpengaruh positif dan signifikan secara parsial terhadap Kinerja Karyawan PT. Pabrik Kertas Tjiwi Kimia Tbk Sidoarjo.

\section{Pengaruh Ruang Lingkup Audit Internal Terhadap Kinerja Staf Quality Control}

Bahwa variabel Ruang Lingkup mempengaruhi variabel Kinerja Staf Quality Control dengan nilai t hitung positif untuk variabel kompetensi 8,073 > t tabel sebesar 1,70814 dengan tingkat signifikansi 0,000 < 0,05. Berarti variabel Ruang Lingkup berpengaruh positif dan signifikan secara parsial terhadap Kinerja Karyawan PT. Pabrik Kertas Tjiwi Kimia Tbk Sidoarjo.

Tabel 4. Uji T Coefficients $a$

\begin{tabular}{|c|c|c|c|c|c|c|}
\hline \multirow[b]{2}{*}{ Model } & & \multicolumn{2}{|c|}{$\begin{array}{l}\text { Unstandardized } \\
\text { Coefficients }\end{array}$} & $\begin{array}{c}\text { Standardized } \\
\text { Coefficients }\end{array}$ & \multirow[b]{2}{*}{$\mathrm{t}$} & \multirow[b]{2}{*}{ Sig. } \\
\hline & & $B$ & $\begin{array}{l}\text { Std. } \\
\text { Error }\end{array}$ & Beta & & \\
\hline 1 & (Constant) & -2.942 & 1.470 & & -2.124 & .044 \\
\hline & Profesionalisme & .276 & .087 & .235 & 3.176 & .004 \\
\hline & Ruang Lingkup & .861 & .107 & .490 & 8.073 & .000 \\
\hline & Independensi & .902 & .143 & .485 & 6.302 & .000 \\
\hline
\end{tabular}

Sumber : Data Primer (2019) 
Pengaruh Independensi Audit Internal Terhadap Kinerja Staf Quality

\section{Control}

Bahwa variabel Independensi mempengaruhi variabel Kinerja Staf Quality Control dengan nilai t hitung positif untuk variabel kompetensi 6,302 > t tabel sebesar 1,70814 dengan tingkat signifikansi $0,000<0,05$. Berarti variabel Independensi berpengaruh positif dan signifikan secara parsial terhadap Kinerja Karyawan PT. Pabrik Kertas Tjiwi Kimia Tbk Sidoarjo.

\section{SIMPULAN}

Berdasarkan penelitian ini dapat diambil suatu kesimpulan yaitu : (1) Terdapat pengaruh secara simultan antara variabel Profesionalisme, Ruang Lingkup dan Independensi terhadap Kinerja Staf Quality Control. (2) Terdapat pengaruh secara parsial profesionalisme, ruang lingkup dan independensi terhadap kinerja staf quality control. Dapat disimpulkan bahwa semakin baik profesionalisme seorang Audit Internal perusahaan, memberikan ruang lingkup kerja yang tidak dibatasi dan Independensi Audit Internal dapat dipertahankan oleh Audit Internal itu sendiri maupun orang-orang dalam perusahaan PT Pabrik Kertas Tjiwi Kimia maka akan semakin baik pula kinerja staf quality control dan sebaliknya semakin buruk Profesionalisme Audit Internal, Ruang lingkup yang dibatasi dan Independensinya tidak ada lagi maka semakin buruk kinerja staf quality control. Dan saran yang dapat peneliti berikan antara lain : (1) Agar menambahkan variabel independen pada faktor-faktor Audit Internal selain profesionalisme, ruang lingkup dan independensi sehingga dapat diperoleh informasi yang lebih lengkap tentang faktor- faktor audit internal yang mempengaruhi kinerja staf quality control. (2) Audit Internal merupakan bagian dari perusahaan yang sangat penting keberadaannya. Oleh sebab itu, maka PT Pabrik Kertas Tjiwi Kimia Tbk Sidoarjo harus menjadikannya sebagai divisi independen agar kualitas dari seorang audit internal dapat terjaga. (3) Bagi penelitian selanjutnya, diharapkan agar menggunakan metode lain selain kuesioner dalam pengumpulan data agar data yang diperoleh lebih valid.

\section{DAFTAR PUSTAKA}

Amin 2016, Peranan audit internal dan sistem akuntansi penjualan terhadap efektivitas internal piutang usaha perusahaan (studi pada PT Pos Indonesia (Persero)). Retrieved 26 Agustus 2017. From http://repository.unpas.ac.id/id/eprint/12033.

Arens et all 2014, Pengaruh kompetensi dan independensi auditor terhadap kualitas audit (pada kantor akuntan publik di wilayah Bandung). Retrived maret 2014.

From http://repository.widyatama.ac.id/xmlui/handle/123456789/3067. 
Kompiang 2018, Pengaruh akuntabilitas dan profesionalisme auditor terhadap kualitas audit internal (studi empiris pada PDAM tirtawening kota Bandung). Retrieved 02 februari 2018. From http://repository.unpas.ac.id/id/eprint/32815.

Romahtun 2018, Pengaruh audit internal, gaya kepemimpinan, motivasi dan disiplin kerja terhadap kinerja karyawan (studi kasus pada PT Bank Pembanguna Daerah Bengkulu), Skripsi, Universitas Islam Indonesia, Yogyakarta.

Setiadi, Angger Eka dan Widianti, Hesti 2016, Pengaruh audit internal terhadap kinerjastaf administrasi (studi kasus di PT Arga Boga Cemerlang tegal), Jurnal riset akuntansi, Vol 5, No. 1, PoliTeknik Harapan Bersama, Tegal. 